\title{
Inclusão de estudante cego em curso de Análise e Desenvolvimento de Sistemas de uma instituição pública de ensino superior: um estudo de caso
}

\author{
Luciano Tadeu Esteves Pansanato* \\ Luzia Rodrigues** \\ Christiane Enéas Silva***
}

\section{Resumo}

A proposta da educação inclusiva tem sido destaque na legislação brasileira nas últimas décadas. Entretanto, a concretização desse modelo é uma das questóes que desafiam o sistema educacional de países do mundo todo, uma vez que requer recursos para adaptação dos ambientes físicos, aquisiçấo de software específico, contratação de profissionais especializados, entre outras necessidades. Neste contexto, o objetivo deste artigo é apresentar as açốes desenvolvidas para permitir a inclusão de um estudante cego na educaçấo superior, por meio de um estudo de caso que teve como participante o próprio aluno. A apresentação deste estudo aborda as açôes iniciais e também as açôes específicas para superar as dificuldades encontradas. Os resultados indicam que as açôes desenvolvidas alcançaram o efeito desejado de promover a inclusão e permanência do estudante cego, visto que ao término do curso este demonstrou domínio das habilidades e competências previstas no projeto político-pedagógico do curso. Espera-se que as açóes apresentadas possam ser repetidas em outras situações nas quais seja necessário realizar práticas inclusivas.

Palavras-chave: Educação superior; Inclusão escolar; Estudante cego; Adaptações curriculares.

\footnotetext{
* Professor doutor da Universidade Tecnológica Federal do Paraná, Cornélio Procópio, Paraná, Brasil.

** Pedagoga da Universidade Tecnológica Federal do Paraná, Cornélio Procópio, Paraná, Brasil.

*** Professora da Universidade Tecnológica Federal do Paraná, Curitiba, Paraná, Brasil.
} 


\section{Inclusion of blind student in Systems Analysis and Development course of a public institution of higher education: a case study}

\section{Abstract}

The proposal of the inclusive education has been prominence in the Brazilian legislation in the last decades. However, the materialization of that model is one of the subjects that challenge the education system of countries of the whole world, once it requests resources for adaptation of the physical environments, acquisition of specific software, recruitment of specialized professionals, among other needs. The aim of this article is to present the actions developed to allow the inclusion of a blind student in higher education, through a case study that had as participant the own student. The presentation of this case study addresses the initial actions and specific actions to overcome the difficulties. The results indicate that the developed actions reached the desired effect of promoting the inclusion and permanence of the blind student, since at the end of the course, the student demonstrated domain of the abilities and competences foreseen in the political-pedagogic project of the course. It is expected that the actions presented can be repeated in other situations in which it is necessary to carry out inclusive practices.

Keywords: Higher education; School inclusion; Blind student; Curricular adaptations.

\section{Introdução}

A concretização do modelo da educaçâo inclusiva é uma das questóes que desafiam o sistema educacional de países do mundo todo, uma vez que demanda recursos para adaptação dos ambientes físicos, aquisição de software específico, contratação de profissionais especializados, entre outras necessidades. A implantaçáo dessa concepção pedagógica também requer o aperfeiçoamento de práticas inclusivas envolvidas no processo de ensino-aprendizagem. $\mathrm{Na}$ educação superior, em especial, o professor deve estar preparado para as questóes que envolvem a inclusão de pessoas com deficiência, uma vez que estas precisam de atendimento especializado para a concretização da aprendizagem. Entretanto, geralmente o professor não tem formação específica para tratar essas questôes e não encontra apoio na literatura, que é bastante limitada em relação à inclusão na educação superior.

As instituições de ensino superior têm desenvolvido esforços para oferecer equipamentos, serviços, estratégias e práticas para atenuar as dificuldades encontradas pelos seus alunos com deficiência e, assim, promover a inclusão educacional no ensino superior em geral. Algumas experiências de sucesso relacionadas à inclusão de estudante cego na educação superior têm sido relatadas na literatura, como em Carvalho et al. (2001), Fortes e Martins (2007), Mantoan et al. (2008) e Rodrigues e Barni (2009). No entanto, poucos trabalhos possuem o foco em cursos da área de 
Inclusão de estudante cego em curso de Análise e Desenvolvimento de Sistemas de uma instituição pública de ensino superior: um estudo de caso

Ciência da Computação, que desperta interesse nas pessoas cegas a partir de sua experiência com computadores e outros recursos tecnológicos.

Os rumos para uma educação inclusiva têm sido delineados por meio de uma série de açôes e reuniôes internacionais realizadas no final dos anos 80 e início dos 90 . No entanto, os seus contornos são realmente estabelecidos na Conferência Mundial sobre Necessidades Educativas Especiais de 1994, realizada em Salamanca (Espanha). Nessa oportunidade, governos e organizaçóes internacionais reconheceram a necessidade e urgência de que o ensino chegasse a todas as crianças, jovens e adultos com necessidades educacionais especiais no âmbito do ensino regular (SÁNCHEZ, 2005). A Declaração de Salamanca (UNESCO, 1994) estabelece estratégias regionais, nacionais e internacionais para a educação inclusiva, com uma nova maneira de pensar a respeito das necessidades especiais, das instituiçôes de ensino, da capacitação dos profissionais da educação e de outros aspectos relacionados à educação.

A educação inclusiva, segundo a Declaração de Salamanca, está centrada principalmente na concepçáo de educação de qualidade para todos e no respeito à diversidade. De maneira mais específica, a educação inclusiva deve ser entendida como uma das tentativas de atender as dificuldades de aprendizagem de qualquer aluno no sistema educacional e como um meio de assegurar que os alunos, que apresentam alguma deficiência, tenham os mesmos direitos que os seus colegas que são escolarizados no ensino regular (SÁNCHEZ, 2005).

A Declaração de Salamanca tornou-se o referencial para a educação inclusiva em vários países. No Brasil, esse documento influenciou a Lei de Diretrizes e Bases da Educação Nacional (BRASIL, 1996), entre outros importantes documentos conseguintes. Em especial, nas Diretrizes Nacionais para a Educaçáo Especial na Educação Básica (BRASIL, 2001), a inclusão é colocada como um processo que pressupóe a reestruturaçáo do sistema educacional envolvendo açóes no projeto pedagógico, formaçấo continuada dos profissionais da educação, e o suporte necessário ao acesso e permanência de todo educando.

O documento Política Nacional de Educação Especial na Perspectiva da Educação Inclusiva (BRASIL, 2008) define novas concepções em relação à atuação da educação especial no sistema educacional brasileiro. Ao invés de substituir o que é ensinado a todos os alunos com e sem deficiência, a educaçáo especial atualmente está centrada em complementar a formação por meio do ensino de conteúdos e utilização de recursos que conferem aos alunos com alguma deficiência a possibilidade de acesso, permanência e participação no ensino regular (do básico ao superior) com autonomia e independência.

A Política Nacional de Educação Especial na Perspectiva da Educação Inclusiva tem como objetivo assegurar a participação e a aprendizagem aos alunos com deficiência, transtornos globais de desenvolvimento e com altas habilidades (ou superdotação) nas escolas comuns de ensino regular, atendendo o princípio constitucional da igualdade de condiçóes de acesso e permanência na escola e continuidade de estudos nos níveis mais elevados de ensino. De acordo com esse objetivo, a educação especial 
é definida como uma modalidade transversal a todos os níveis, etapas e modalidades, que atua de forma complementar ou suplementar ao ensino regular, disponibilizando serviços e recursos para as atividades de atendimento educacional especializado e a promoção da acessibilidade nos ambientes e processos educacionais (BRASIL, 2008).

No contexto da educação inclusiva, adaptações curriculares ou adequações curriculares $^{1}$ são expressōes empregadas para denominar toda e qualquer ação pedagógica realizada pelo sistema educacional que tenha a intençáo de flexibilizar o currículo para oferecer respostas educativas às necessidades especiais dos alunos (BRASIL, 1998). As necessidades educacionais especiais revelam quais estratégias, diferentes das usuais, são necessárias para permitir que todos os alunos, inclusive aqueles com deficiência, participem integralmente das oportunidades educacionais, com resultados favoráveis, dentro de uma programaçáo tâo normal quanto possível.

As adaptaçôes curriculares podem ser de dois tipos (BRASIL, 2000): adaptaçóes curriculares de grande porte e adaptaçóes curriculares de pequeno porte. As adaptaçóes curriculares de grande porte, denominadas originalmente de significativas (BRASIL, 1998), compreendem as açôes que são de competência e atribuição das instâncias político-administrativas superiores, considerando que exigem modificaçôes que envolvem açôes de natureza política, administrativa, financeira, burocrática, etc. As adaptaçóes curriculares de pequeno porte, denominadas originalmente de não significativas (BRASIL, 1998), compreendem as modificaçóes menores, de competência específica do professor, não exigindo autorização, nem dependendo de ação de qualquer outra instância superior nas áreas política, administrativa e/ou técnica. As adaptaçóes curriculares de pequeno porte são pequenos ajustes nas açóes planejadas a serem desenvolvidas no contexto da sala de aula.

De maneira geral, as adaptações curriculares de grande porte são úteis para atender à necessidade especial do aluno quando houver discrepância entre suas necessidades e as exigências do currículo regular à medida que se amplia a complexidade das atividades acadêmicas. $\mathrm{O}$ objetivo é permitir aos alunos com deficiência que apresentam necessidades educacionais especiais o alcance de objetivos educacionais que sejam viáveis e significativos, em um ambiente inclusivo e na convivência com seus pares.

Existem várias categorias de adaptações curriculares de grande porte, que são definidas de acordo com os elementos curriculares nos quais estão inseridas: adaptaçóes de acesso ao currículo; adaptaçáo de objetivos; adaptação de conteúdos; adaptaçóes do método de ensino e da organizaçáo didática; adaptaçáo do sistema de avaliação; adaptação de temporalidade.

As adaptaçôes curriculares de pequeno porte geralmente são empregadas para permitir e promover a participação produtiva dos alunos com necessidades especiais no ensino regular e com os seus colegas. Essas adaptaçôes podem se realizar no âmbito das mesmas categorias das de grande porte, com a diferença de que são de atribuição e responsabilidade exclusivas do professor, em suas açôes na sala de aula: adaptação de objetivos; adaptação de conteúdos; adaptaçóes do método de ensino e da organi- 
Inclusão de estudante cego em curso de Análise e Desenvolvimento de Sistemas de uma instituição pública de ensino superior: um estudo de caso

zação didática; adaptação do processo de avaliação; adaptação na temporalidade do processo de ensino e aprendizagem.

\section{Método}

Neste artigo são investigadas as ações realizadas para permitir a inclusão e permanência de um estudante cego na educação superior, empregando como metodologia o estudo de caso. A escolha pelo estudo do caso é devido à abordagem qualitativa do método e à natureza, também qualitativa, dos dados disponíveis.

\section{Participantes}

O estudo de caso apresentado é centrado em um único participante: um estudante cego matriculado no curso de graduação em Análise e Desenvolvimento de Sistemas. O espaço de atuação é delimitado à Instituição Pública de Ensino Superior, isto é, não são consideradas as ações realizadas fora do âmbito desta instituição. $\mathrm{O}$ período de tempo do estudo de caso é do segundo semestre de 2007, matrícula no curso, ao segundo semestre de 2012, formatura no curso, caracterizando um estudo de caso longitudinal (MALHEIROS, 2011).

O sujeito deste estudo de caso, com 35 anos em 2012, é do sexo masculino, funcionário público estadual, casado e é pai de duas filhas. $\mathrm{O}$ sujeito perdeu a visão do olho esquerdo aos quatro anos de idade devido à catarata congênita e perdeu totalmente a visão aos nove anos de idade decorrente de complicaçóes de uma cirurgia para corrigir um descolamento de retina.

Depois de um período de quatro anos fora do ensino regular, aos treze anos o sujeito passou a frequentar uma sala especial para estudantes com deficiência visual, quando aprendeu o sistema braile e a utilizar o sorobá. Aos catorze anos retomou os estudos da quarta série no ensino regular e foi promovido para a quinta série por meio de uma reclassificação, cursando até a oitava série.

No ensino médio cursou Auxiliar Técnico em Contabilidade até 1996, prestou dois vestibulares, mas não foi aprovado. Em 1999 foi aprovado em concurso público para um cargo na secretaria de uma escola municipal, mas foi remanejado para trabalhar na biblioteca. O primeiro contato com a informática foi por meio de um curso de treinamento em um software leitor de tela promovido por uma fundaçáo de apoio. Em 2005 foi aprovado em concurso público para técnico-administrativo de uma escola estadual. O sujeito foi aprovado no vestibular de junho de 2007 (na sua segunda tentativa) para o curso de graduação em Análise e Desenvolvimento de Sistemas da Instituição Pública de Ensino Superior.

\section{Procedimentos para coleta de dados}

A principal fonte de informaçóes para este estudo de caso foram os relatórios semestrais da tutoria especial, que descrevem as atividades realizadas para apoiar o estudante cego em cada uma das disciplinas. Para obter informaçóes referentes ao período anterior à implantação da tutoria especial foi necessário consultar os professores e o próprio estudante cego. Algumas informações adicionais também foram obtidas da equipe pedagógica que realizou o acompanhamento do estudante cego. 


\section{Resultados e discussão}

A análise das informações obtidas foi realizada segundo algumas dimensões as quais são utilizadas para organizar a apresentação desta seção: "Açôes Iniciais", "Acesso a Material Didático Adaptado e Alternativo"; "Diagramas e Estudantes Cegos"; "Adaptaçóes Curriculares".

\section{Ações iniciais}

O caso em questão teve início com a matrícula, em 2007, de um estudante cego no curso de graduação em Análise e Desenvolvimento de Sistemas. A primeira ação foi realizar uma entrevista com o estudante para conhecer suas preferências, habilidades e limitações. Esse tipo de ação é importante para obter informações para auxiliar a definição de estratégias iniciais de inclusão (REGIANI; MÓL, 2013; RODRIGUES; BARNI, 2009; FERREIRA, 2007). Por exemplo, por meio da entrevista obteve-se a informação de que o estudante utilizava pouco o sistema braile e que preferia ter acesso a textos longos no computador por meio de um software leitor de tela. Para atender a essa necessidade, a Universidade forneceu um computador portátil para o estudante e o software leitor de tela de sua preferência foi obtido por meio de doação de uma empresa.

A preferência pelo acesso a textos com o uso de um software leitor de tela não significa que a leitura braile não foi utilizada pelo estudante cego. Ao contrário, o conhecimento do sistema braile foi útil para a leitura das legendas inseridas nas diversas representaçóes táteis criadas como recurso de apoio ao ensino. $\mathrm{O}$ uso do sistema braile é muito mais amplo que somente a leitura de textos longos como aqueles encontrados em livros (TORRES et al., 2007). Por exemplo, a leitura braile também é importante para consultar a informação contida em etiquetas de objetos (de uso diário por uma pessoa cega), placas de orientação, botốes de elevador etc.

Embora o sistema braile seja um recurso importante para o estudante cego, o computador, complementado pelo software leitor de tela, pode ser considerado a ferramenta fundamental para o sucesso de sua inclusáo. A utilizaçáo desse suporte auxiliou na comunicaçáo do estudante cego com os seus colegas de classe e com outras pessoas sem deficiência do ambiente universitário, e também auxiliou no acesso, em geral, à informação e aos diversos materiais utilizados no processo de ensino-aprendizagem. Nesse sentido, a tecnologia tem auxiliado os estudantes cegos a superar barreiras para a participação social e a aprendizagem (ALBERNAZ et al., 2011; MANZINI, 2005; SANTAROSA, 2000).

Através da experiência adquirida no acompanhamento das atividades realizadas pelo estudante cego, observou-se que é desejável que uma pessoa com deficiência visual, ao matricular-se na educação superior em computação, tenha o domínio das seguintes competências:

a) Conhecer o teclado do computador e a navegação pelo teclado;

b) Utilizar um software leitor de tela e ter o ouvido treinado na audição de voz sintetizada; 
Inclusão de estudante cego em curso de Análise e Desenvolvimento de Sistemas de uma instituição pública de ensino superior: um estudo de caso

c) Manipular os elementos básicos do sistema operacional;

d) Utilizar um editor de texto para leitura e produção de documentos;

e) Utilizar um navegador para acesso à Web;

f) Receber e enviar e-mails.

Caso o estudante não tenha o domínio necessário dessas competências é importante que a instituição de ensino ofereça o treinamento necessário em tempo para o início de suas atividades. Essa ação é considerada como um serviço de atendimento de reabilitação (área de apoio de Comunicação), de acordo com o Manual Técnico de Serviços de Reabilitação Integral (ULAC, 2000). O tempo necessário para que uma pessoa cega tenha o domínio básico dessas competências pode variar, pois depende muito do seu conhecimento prévio. Por exemplo, professores que atuaram no Câmpus em cursos de qualificaçáo profissional (para o primeiro emprego) direcionados para pessoas cegas e com baixa visão estimam que sejam necessárias de 30 a 40 horas de treinamento para adquirir essas competências. Essa informação foi obtida por meio de entrevistas informais com esses professores.

Ainda como parte das açôes iniciais, os professores da área e a equipe pedagógica visitaram o Centro de Atendimento Especializado para Deficientes Visuais e Auditivos do município para receber orientaçôes sobre a aprendizagem de pessoas com deficiência visual e também sobre a adaptaçáo de materiais de apoio. Posteriormente, duas professoras desse centro foram convidadas e compareceram no Câmpus para orientar a equipe pedagógica e os assistentes de ensino quanto aos procedimentos adequados para guiar o estudante cego nas dependências da Universidade. Adicionalmente, quanto às estratégias gerais que devem ser adotadas pelo professor em sala de aula, algumas das orientaçóes podem ser assim resumidas:

- Ler em voz alta enquanto estiver escrevendo no quadro;

- Fornecer informaçôes verbais sobre os eventos ocorridos em sala de aula;

- Informar sobre as mudanças na organização da sala de aula;

- Observar os sinais de cansaço e permitir a realização de pausas;

- Atribuir o tempo necessário para a realização de tarefas de maior esforço, em especial, a leitura de textos longos.

A maior dificuldade dos professores nesse contexto foi a falta de treinamento adequado para trabalhar com o estudante cego. A preparação dos professores é de extrema importância, pois estes têm a responsabilidade de conduzir o processo de ensino-aprendizagem (VITALIANO, 2007; MICHELS; DELLECAVE, 2005). Nesse contexto, além do investimento da instituição de ensino em capacitação pedagógica, também é importante o diálogo com o estudante cego para o professor conhecer as suas preferências e dificuldades e melhor contribuir para uma formação com qualidade. 


\section{Acesso a material didático adaptado e alternativo}

No primeiro período do curso, o estudante cego realizou as disciplinas previstas no currículo regular com ótimo desempenho. As disciplinas desse período ou dependiam apenas de leitura e produção de texto (por exemplo, Comunicação Linguística e Organização Empresarial) ou exigiam pouco material adaptado (por exemplo, Fundamentos Matemáticos). No primeiro caso, o material utilizado em aula sempre era fornecido com antecedência ao estudante cego e, no segundo caso, o professor elaborou representaçôes táteis (gráficos com o uso de materiais simples como cartolina, barbante e cola relevo) como apoio ao ensino de determinados conteúdos (por exemplo, gráficos de funçôes). Para um estudante cego, o uso da percepção tátil é essencial para o desenvolvimento da capacidade de organizar, transferir e abstrair conceitos (NUNES; LOMÔNACO, 2008; OLIVEIRA et al., 2003).

A açáo de proporcionar maneiras diferenciadas de acesso ao material utilizado nas disciplinas, seja adequando o material existente e/ou disponibilizando material alternativo, exige um esforço adicional do professor para o qual ele deve estar preparado e bem orientado a respeito. Por exemplo, o professor deve criar as suas apresentaçôes (por exemplo, por meio do PowerPoint) com legenda nas imagens, diagramas e nos gráficos e enviar esse material com antecedência para o estudante cego, e também evitar utilizar arquivos PDF do tipo imagem porque não são acessíveis a um software leitor de tela.

A busca de material alternativo na Web pelo próprio estudante foi sempre bastante incentivada. Entretanto, o estudante encontra dificuldades nessa tarefa devido às páginas que não estão em conformidade com as principais recomendaçôes de acessibilidade de conteúdo da Web (MELO et al., 2009). Por exemplo, quando uma página com barreiras de acessibilidade é carregada no navegador, o software leitor de tela pode "ficar mudo", se a página utiliza elementos gráficos em excesso, ou pode "ler" o conteúdo de maneira desordenada, impossibilitando em ambos os casos o acesso à informação contida na página. A principal dificuldade encontrada pelo estudante cego não foi no uso de um sistema de busca (por exemplo, Google ou Yahoo! Search), mas sim na tarefa de avaliar e selecionar o que foi encontrado a partir da lista de resultados apresentada, pois frequentemente isso envolve visitar cada um dos itens (links) considerados de interesse.

Esse período coincidiu com a adoção do software Moodle (http://moodle.org) pela Universidade. O Moodle é um ambiente virtual de aprendizagem (AVA), utilizado principalmente como ferramenta de apoio às aulas presenciais, e também para o gerenciamento (pelo professor) das atividades práticas supervisionadas realizadas a distância, isto é, planejadas como trabalho extraclasse e com o acompanhamento do professor da disciplina. No entanto, usuários que possuem limitaçóes, ao interagirem com ambientes virtuais, muitas vezes têm dificuldades de acesso, navegação ou não compreendem as informaçóes veiculadas (SONZA et al., 2008).

Diversos estudos analisam o Moodle sob os aspectos relacionados à acessibilidade de usuários com deficiência visual (ULBRICHT et al., 2011; COELHO et al., 2011; JATOBÁ et al., 2009). A maior dificuldade encontrada pelo estudante cego foi 
no início do uso do Moodle, porque a quantidade de elementos existentes na página exige um esforço grande para serem percebidos durante a navegação. Além disso, apesar de esse sistema seguir muitas das recomendaçóes de acessibilidade na Web, o estudante também teve dificuldades no uso de alguns de seus recursos, por exemplo, no preenchimento de determinados campos de questionário, na alteração de suas informaçôes de perfil e na atividade de elaborar documentos colaborativamente (conhecida por $\mathrm{Wiki}^{2}$ ). Apesar desses problemas, o uso do Moodle foi considerado altamente positivo pelo estudante cego devido à facilidade do acesso às notas de aula e outros materiais didáticos, e também pela entrega de tarefas por meio do carregamento de arquivos.

\section{Diagramas e estudantes cegos}

No segundo período do curso, os professores encontraram dificuldades quando o desenvolvimento de conceitos envolvia estratégias de ensino apoiadas em diagramas, como na representaçáo de estruturas de dados abstratas (por exemplo, árvores e grafos) e em técnicas visuais de projeto de banco de dados. Em geral, as dificuldades encontradas por estudantes cegos ocorrem nos conteúdos que se apoiam fortemente na visualização de fenômenos ou situaçóes (DICKMAN; FERREIRA, 2008). Inicialmente, foi suficiente o uso de cartolina, madeira e fixação com velcro para criar o material de apoio básico. Por exemplo, na Figura 1 é mostrada uma mesa didática construída especialmente para o ensino de árvores e grafos.

Figura 1 - Visão geral da mesa didática (à esquerda) e da identificação do rótulo utilizando o sistema braile e detalhe da fixaçấo com velcro (à direita).

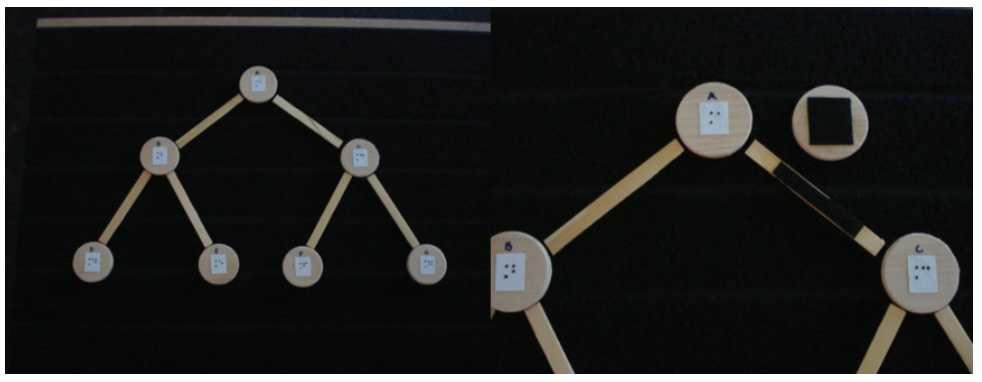

Uma das açóes realizadas nesse contexto foi a implantação de tutoria especial com o objetivo principal de acompanhar e auxiliar o estudante cego nas disciplinas que utilizam técnicas e ferramentas visuais de modelagem de sistemas de informação. Esse tipo de apoio, quando oferecidos no contexto do ensino regular, é denominado de serviço de apoio pedagógico especializado (HEREDERO, 2010). O trabalho de tutoria especial foi implantado com a contratação de uma pessoa com formação na área de computaçáo. O estudante cego participava das aulas das disciplinas com os seus colegas e com o acompanhamento do tutor, que avaliava o plano de aula previamente com o professor, coordenador de curso e equipe pedagógica, e estabeleciam as estratégias para o processo de ensino-aprendizagem com base nas informaçóes obtidas com o estudante com relação às suas dificuldades e preferências. Ressalta-se 
a importância do trabalho cooperativo entre o professor, coordenador de curso, e equipe pedagógica, o tutor e o estudante (HEREDERO, 2010).

O tutor também foi responsável pelo desenvolvimento do material didático específico e/ou adaptação dos materiais existentes utilizados nas disciplinas. A adequação de materiais tem o objetivo de garantir o acesso às mesmas informaçóes que os outros estudantes, para que o estudante cego não esteja em desvantagem em relação aos seus colegas (NUNES; LOMÔNACO, 2010). Em especial, o tutor desenvolveu algumas das representaçóes táteis que foram utilizadas nas disciplinas utilizando somente materiais simples, por exemplo, papel cartáo e EVA, metal e ímá entre outros. Na Figura 2 são mostrados dois exemplos do material produzido.

Figura 2 - Um imantógrafo construído com uma chapa de metal riscada e recortes de imá (manta magnética) (à esquerda) e uma representação tátil construída principalmente com papel cartão e EVA (à direita).

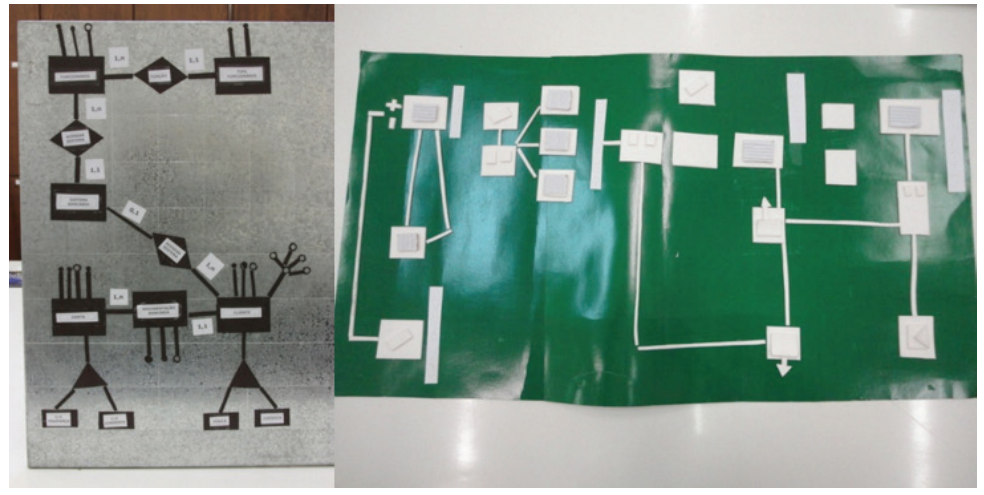

Posteriormente, o material didático foi produzido também com o auxílio de equipamentos específicos como impressora braile, impressora de relevos e mesa de relevos táteis. Esses equipamentos foram adquiridos com recursos do Programa de Acessibilidade na Educação Superior (Incluir) (BRASIL, 2009). A impressora braile é um tipo de impressora de impacto e a impressora de relevos utiliza um papel especial que reage ao calor para formar o relevo. A representação tátil de um diagrama produzida por uma impressora de relevos pode ser combinada com uma mesa de relevos táteis na qual é colocado o diagrama e, por intermédio da seleção por toque, são emitidas informações em áudio previamente programadas. A adequação do material didático para empregar essa estratégia de audiodescrição combinada com a representação tátil do diagrama foi realizada pelo tutor com base no material didático utilizado na disciplina. O professor da disciplina fornecia as orientaçôes necessárias para o tutor e verificava a qualidade do material produzido. Na Figura 3 são mostradas a impressora de relevos e a mesa de relevos táteis. 
Inclusão de estudante cego em curso de Análise e Desenvolvimento de Sistemas de uma instituição pública de ensino superior: um estudo de caso

Figura 3 - Impressora de relevos (à esquerda) e mesa de relevos táteis (à direita).

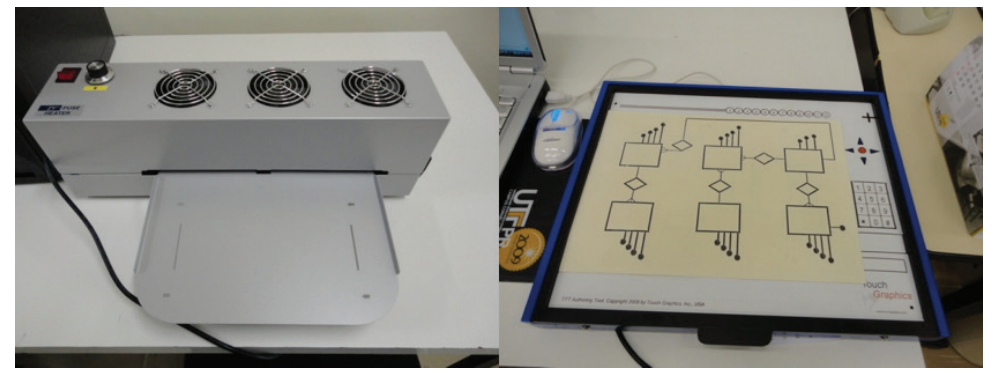

A qualidade e a velocidade na produção de representaçôes táteis com o uso desses equipamentos (Figura 3) são muito superiores à construção manual com o uso de materiais simples. Entretanto, foi observado que o uso da mesa de relevos táteis em sala de aula causava constrangimento ao estudante cego devido à quantidade de equipamento que deve ser instalado para seu uso exclusivo (o equipamento requer um computador acoplado). Por essa razão, a mesa de relevos táteis não foi mais utilizada em sala de aula. Além disso, também foram observadas desvantagens semelhantes às da máquina de escrever braile que, apesar de compacta, pesa 4,5 quilos e é barulhenta (REILY, 2004).

As representaçóes táteis produzidas foram importantes para o sucesso no ensino dos conceitos subjacentes às diversas notaçôes gráficas utilizadas para especificar, construir e documentar artefatos de sistemas/software, incluindo também outros tipos de diagramas essenciais ao ensino de computação (por exemplo, os relacionados a redes de computadores). Na literatura existem alguns trabalhos (BROOKSHIRE, 2006; FRANCIONI; SMITH, 2002) que descrevem a aplicação de representações táteis no ensino de diagramas para estudantes cegos. No entanto, esse trabalho ainda exige pessoal dedicado, principalmente na produção de representações táteis e na configuração da mesa de relevos táteis. Nesse contexto, o tutor dispôe do auxílio de um estagiário para conseguir atender a demanda de todas as disciplinas.

Outro problema relacionado com o uso de representaçôes táteis foi encontrado no desenvolvimento de trabalhos em grupo, durante a comunicação entre o estudante cego e os estudantes sem deficiência visual, principalmente quando estavam trabalhando no mesmo exercício ou projeto. Como essa atividade é dinâmica, o estudante cego tem dificuldade de acompanhar as etapas intermediárias da construção de um diagrama complexo. A produção de representaçôes táteis a cada alteraçâo proposta por um dos integrantes do grupo ao longo do trabalho é inviável.

Para minimizar essa dificuldade com as representaçôes táteis, os professores utilizaram uma representaçáo alternativa para diagramas que utiliza uma tabela ao invés de elementos gráficos. Basicamente, a técnica consiste em representar o diagrama na tabela como um grafo de nós (vértices) e arcos (arestas), na qual as colunas contêm informaçóes sobre os nós iniciais (origem dos arcos) e finais (destino dos arcos) e as linhas da tabela representam os arcos do grafo. Essa técnica permite que um estudan- 
te cego possa entender e construir um diagrama nessa representação sem o auxílio de outra pessoa ou de qualquer equipamento especial que não aqueles usualmente utilizados por um usuário cego. A tabela pode ser construída em um programa aplicativo do tipo planilha eletrônica (por exemplo, Microsoft Excel) cujas células geralmente são acessíveis utilizando um software leitor de tela e a navegação pelo teclado. $\mathrm{Na}$ Figura 4 é mostrado um exemplo de um diagrama e a sua representação em tabela. Essa representação foi aplicada com sucesso no processo de ensino-aprendizagem de diversas técnicas de modelagem com base em diagramas (SILVA, C. E.; PANSANATO, L. T. E.; FABRI, J. A., 2010).

Figura 4 - Exemplo de um diagrama e a sua representação equivalente utilizando uma tabela

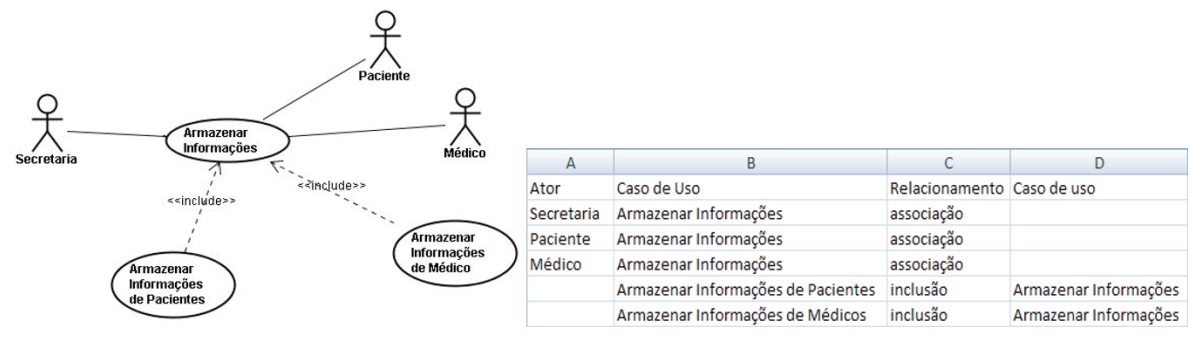

A representação em tabela de diagramas permite ao estudante cego adquirir e aplicar os principais conceitos empregados nas técnicas visuais de modelagem de sistemas. O professor, por sua vez, utiliza a representação em tabela como apoio ao processo de ensino-aprendizagem do conteúdo. É importante ressaltar, entretanto, que apesar de facilitar a comunicação entre professor e estudante, o uso dessa representação alternativa não altera a curva de aprendizagem inerente ao conteúdo. $\mathrm{O}$ desenvolvimento da habilidade de realizar as abstraçôes e elaborar modelos representativos ocorre de maneira semelhante que com o uso da notação gráfica (SILVA, C. E.; PANSANATO, L. T. E.; FABRI, J. A., 2010).

\section{Adaptações curriculares}

No caso em questão, o conteúdo programático proposto para atender a ementa das disciplinas do curso foi adequado para o estudante cego com o objetivo de proporcionar um melhor domínio das habilidades e competências necessárias para a sua formação com qualidade equivalente aos estudantes sem deficiência. As adaptaçôes curriculares realizadas foram do tipo de pequeno porte (BRASIL, 2000), uma vez que não houve discrepância entre as necessidades do estudante cego e as exigências do currículo regular (ementa das disciplinas). As adaptaçôes curriculares de pequeno porte são realizadas pelo professor para que os alunos possam conseguir as capacidades expressas no currículo oficial; são pequenos ajustes nos conteúdos, formas de ensinar, na sequência e planificação de conteúdos e tarefas; ou até nas estratégias de avaliação, procedimentos de avaliação ou recursos utilizados (HEREDERO, 2010).

Para cada disciplina, foi realizada uma rigorosa avaliaçáo do conteúdo programático da disciplina, na qual participavam o professor, tutor, coordenador de curso e a equipe pedagógica. De fato, a elaboração e o desenvolvimento de adaptaçóes cur- 
riculares é um processo compartilhado de tomada de decisōes (HEREDERO, 2010). Após a avaliação, uma ou mais das seguintes estratégias (abstraídas como resultado deste estudo de caso) foram adotadas com relação aos conteúdos planejados pelo professor para atender a ementa da disciplina:

- Adaptação de conteúdos. O pressuposto para a adaptação de conteúdos é que um estudante cego pode aprender todos os conteúdos propostos para a disciplina, desde que the sejam proporcionadas maneiras adequadas de acesso. $\mathrm{O}$ objetivo a ser alcançado com essa estratégia é a manutençấo dos mesmos conteúdos que são ensinados aos estudantes sem deficiência visual.

- Substituição de conteúdos. O pressuposto para a substituição de conteúdos é que um estudante cego pode aprender outros conteúdos em substituição aos conteúdos nos quais a visão desempenha um papel determinante. $\mathrm{O}$ objetivo é não causar afastamento dos conteúdos propostos para a disciplina (e que atendem os objetivos e a ementa), mas introduzir um conteúdo equivalente em substituição ao que geralmente era proposto pelo professor para atender a ementa da disciplina.

- Expansão de conteúdos. O pressuposto para a expansão de conteúdos é que um estudante cego pode aprender conteúdos adicionais sempre que isso possa contribuir para a melhoria da sua autonomia, da qualidade de seu desempenho e do domínio das suas competências e habilidades. O objetivo é oferecer algo adicional aos conteúdos propostos para a disciplina e que seja adequado para a ampliaçáo das oportunidades de acesso ao mercado de trabalho.

A adaptação de conteúdos foi a estratégia adotada com maior frequência. Essa adaptação envolveu pequenos ajustes no plano de aula da disciplina visando o acesso pelo estudante cego. Nessa estratégia, os conteúdos propostos para a disciplina foram ministrados da mesma maneira para o estudante cego e para os estudantes sem deficiência. Por exemplo, os professores da disciplina Redes de Computadores geralmente alinham parte do conteúdo com aqueles oferecidos em programas de certificação profissional, mas geralmente o material didático empregado nestes programas, que não é acessível, deve ser adaptado.

A substituição de conteúdos ocorreu com frequência nas disciplinas que trabalhavam interface gráfica com o usuário e técnicas visuais de modelagem. Por exemplo, os professores da disciplina Análise de Sistemas, ao invés dos diagramas tradicionais e suporte computacional associado (software), utilizaram uma representação alternativa (tabelas), pois a visão assume um papel importante no ensino de diagramas gráficos, os quais são parcialmente ou totalmente inacessíveis a estudantes cegos. Nesse caso, o conteúdo proposto referente às ferramentas utilizadas para elaborar os diagramas foi substituído sem qualquer prejuízo para o atendimento à ementa da disciplina.

A expansão de conteúdos foi a estratégia menos empregada, principalmente para evitar uma carga de trabalho excessiva para o estudante cego. No entanto, quando um conteúdo novo foi proposto para a turma toda como algo adicional aos conteúdos propostos para a disciplina, o estudante cego sempre respondeu à proposta com 
interesse e motivação. Por exemplo, na disciplina Interação Humano-Computador são trabalhados os conceitos de acessibilidade e tecnologia assistiva. Nesse contexto, o professor também trabalhou os recursos de determinada linguagem de programação para a construção de interfaces acessíveis em sistemas de informação, conteúdo este que não é geralmente previsto no plano de ensino dessa disciplina. Posteriormente, esse conteúdo foi importante para o estudante cego na definição e realização do seu trabalho de conclusão de curso.

\section{Considerações finais}

Neste trabalho foram apresentadas as ações desenvolvidas em uma Instituição Pública de Ensino Superior para permitir a inclusão de um estudante cego no curso de Análise e Desenvolvimento de Sistemas. As informaçóes deste estudo de caso foram organizadas segundo as dimensóes de Açóes Iniciais, Acesso a Material Didático Adaptado e Alternativo, Diagramas e Estudantes Cegos, e Adaptaçóes Curriculares.

Em 2012, o estudante cego apresentou o seu Trabalho de Conclusão de Curso e participou da cerimônia de colação de grau. Além disso, também participou no período 2010-2011 como voluntário (sem bolsa devido ao vínculo empregatício) do Programa Institucional de Bolsas de Iniciaçáo em Desenvolvimento Tecnológico e Inovaçáa (PIBITI), programa apoiado com recursos do CNPq. Atualmente, prossegue seus estudos cursando pós-graduação lato sensu (especialização).

O domínio das habilidades e competências demonstrado pelo estudante cego indica que as açóes realizadas tiveram o efeito desejado de promover a sua inclusáo na educação superior em computaçáa. Portanto, pode-se concluir que o objetivo de permitir a inclusão educacional do estudante cego no curso foi atingido e as açóes realizadas para que isso fosse possível tiveram um papel determinante para este sucesso. A expectativa é que as açóes empreendidas possam ser repetidas com sucesso em outras situaçôes nas quais seja necessário realizar práticas inclusivas com estudantes cegos.

\section{Referências}

ALBERNAZ, N. H. C.; ELIA, M. F.; BORGES, J. A. S. Digitavox: curso de digitação com acessibilidade para deficientes visuais. In: Simpósio Brasileiro de Informática na Educação, 22., Aracaju, 2011. Anais... Porto Alegre: SBC, 2011. p. 558-567.

BRASIL. Diretrizes Nacionais para a Educação Especial na Educação Básica. Brasília: MEC/SEESP, 2001. Lei de Diretrizes e Bases da Educação Nacional. Brasília: MEC, 1996.

Ministério da Educação. Secretaria de Educação Especial. Programa Incluir. 2009. Disponível em: $<$ http://portal.mec.gov.br/index.php?option=com_content\&view= article\&id=12257>. Acesso em: 19 mar. 2011.

Ministério da Educação. Secretaria do Ensino Fundamental. Secretaria de Educação Especial. Parâmetros curriculares nacionais. Adaptaçóes curriculares. Estratégias para a educaçáo de alunos com necessidades educacionais especiais. Brasília: MEC/SEF/SEESP, 1998. ESP, 2008 .

Política Nacional de Educaçáo Especial na Perspectiva da Educaçáo Inclusiva. Brasília: MEC/SE-

Projeto Escola Viva - Garantindo o acesso e permanência de todos os alunos na escola - Alunos com necessidades educacionais especiais. Brasília: MEC/SEESP, 2000.

BROOKSHIRE, R. G. Teaching UML database modeling to visually impaired students. Issues in Information Systems, v. 7, n. 1, p. 98-101, 2006. 
CARVALHO, J. O. F.; ARANHA, M. C. L. F. M.; MORAES, M. C. M. Apoiando os deficientes visuais no ensino superior: o projeto de acessibilidade aos alunos da PUC Campinas. In: Seminário ATIID - Acessibilidade, Tecnologia da Informação e Inclusão Digital, 1, São Paulo, 2001. Anais... São Paulo: USP, 2001.

COELHO, C. M.; et al. Acessibilidade para pessoas com deficiência visual no Moodle. Linhas Críticas, v. 17, n. 33, p. 327-348, 2011.

COHEN, R. F.; MEACHAM, A.; SKAFF, J. Teaching graphs to visually impaired students using an active auditory interface. SIGCSE Bulletin. v. 38, n. 1, p. 279-282, 2006.

DICKMAN, A. G.; FERREIRA, A. C. Ensino e aprendizagem de Física a estudantes com deficiência visual: desafios e Perspectivas. Revista Brasileira de Pesquisa em Educação em Ciências, v. 8, n. 2, 2008.

FERREIRA, S. L. Ingresso, permanência e competência: uma realidade possível para universitários com necessidades educacionais especiais. Revista Brasileira de Educaçáo Especial, v. 13, n. 1, p. 43-60, 2007.

FORTES, V. G. G. F.; MARTINS, L. A. R. O Curso de Filosofia da UFRN diante da inclusão da pessoa com deficiência visual: um estudo de caso. In: MARTINS, L. A. R.; et al. (Orgs.). Educaçáo e inclusáo social de pessoas com necessidades especiais: desafios e perspectivas. João Pessoa: Editora da UFPB, 2007. v. 1, p. $177-184$.

FRANCIONI, J. M.; SMITH, A. C. Computer science accessibility for students with visual disabilities. Special Interest Group on Computer Science Education (SIGCSE) Bulletin. v. 34, n. 1, p. 91-95, 2002.

HEREDERO, E. S. A escola inclusiva e estratégias para fazer frente a ela: as adaptaçóes curriculares. Acta Scientiarum. Education, v. 32, n. 2, p. 193-208, 2010.

JATOBÁ, A.; et al. Ampliando horizontes de aprendizagem: ensaios sobre o uso do moodle por deficientes visuais. In: Congreso Internacional de Educación a Distancia, 13., Concepción, Chile, 2009. Anais... Santiago: CREAD, 2009.

MALHEIROS, B. T. Metodologia da Pesquisa em Educaçáo. Rio de Janeiro: LTC, 2011.

MANTOAN, M. T. E.; BARANAUSKAS, M. C. C.; CARICO, J. S. A. Todos Nós - Unicamp acessível. In: MANTOAN, M. T. E. (Org.). O desafio das diferenças nas escolas. Petrópolis: Vozes, 2008.

MANZINI, E. J. Tecnologia assistiva para educação: recursos pedagógicos adaptados. In: Ensaios pedagógicos: construindo escolas inclusivas. Brasília: SEESP/MEC, 2005. p. 82-86.

MELO, A. M.; ALMEIDA, L. D. A.; SANTANA, V. F. Acessibilidade na Web. In: MANTOAN, M. T.; BARANAUSKAS, M. C. C. (Orgs.) Atores da inclusão na universidade: formaçáo e compromisso. Campinas: UNICAMP/Biblioteca Central Cesar Lattes, 2009. p. 101-128.

MICHELS, L. R. F.; DELLECAVE, M. R. O que os professores têm a dizer sobre a educação inclusiva na universidade. Contrapontos, v. 5, n. 2, p. 469-481, 2005.

NUNES, S. S.; LOMÔNACO, J. F. B. Desenvolvimento de conceitos em cegos congênitos: caminhos de aquisiçẫo do conhecimento. Revista Semestral da Associaçáo Brasileira de Psicologia Escolar e Educacional, v. 12 , n. 1 , p. $119-138,2008$.

NUNES, S. S.; LOMÔNACO, J. F. B. O aluno cego: preconceitos e potencialidades. Revista Semestral da Associaçáo Brasileira de Psicologia Escolar e Educacional, v. 14, n. 1, p. 55-64, 2010.

OLIVEIRA, F. I. W.; BIZ, V. A.; FREIRE, M. Processo de inclusão de alunos deficientes visuais na rede regular de ensino: confecção e utilização de recursos didáticos adaptados. Marília: UNESP, 2003. Disponível em: <http://www.unesp.br/prograd/PDFNE2003/Processo de inclusao de alunos deficientes visuais.pdf $>$. Acesso em: 14 nov. 2013.

REGIANI, A. M.; MÓL, G. S. Inclusão de uma aluna cega em um curso de licenciatura em Química. Ciência \& Educação, v. 19, n.1, 2013.

REILY, L. Escola inclusiva: linguagem e mediação. 2. ed. Campinas: Papirus, 2004.

RODRIGUES, K. G.; BARNI, E. M. A Utilizaçāo de Recursos Tecnológicos com Alunos Deficientes Visuais no Curso Superior a Distância de uma Instituiçáo de Ensino de Curitiba-PR. In: Congresso Nacional de Educação, 9., 2009, Curitiba. Anais... Curitiba: Editora Champagnat, 2009. p. 9240-9251.

SÁNCHEZ, P. A. A educação inclusiva: um meio de construir escolas para todos no século XXI. Inclusão Revista da Educaçáo Especial, n. 1, p. 7-18, 2005. 
SANTAROSA, L. M. C. Telemática y la inclusión virtual y social de personas com necesidades especiales: un espacio posible en la Internet. In: Congreso Iberoamericano de Informatica Educativa, 5, 2000, Viña del Mar, Chile. Anais... Viña del Mar, 2000.

SILVA, C. E.; PANSANATO, L. T. E.; FABRI, J. A. Ensinando Diagramas UML para Estudantes Cegos. In: XVIII Congreso Iberoamericano de Educación Superior en Computación - CLEI 2010 XXXVI Conferencia Latinoamericana de Informática, 2010, Asunción. Anais... Asunción, 2010.

SONZA, A. P.; SANTAROSA, L.; CONFORTO, D. Ambientes Virtuais Acessíveis sob a perspectiva de usuários deficientes visuais. In: Simpósio Brasileiro de Informática na Educação, 19, Fortaleza, 2008. Anais... Porto Alegre: SBC, 2008. p. 74-83.

TORRES, E. F.; MAZZONI, A. A.; MELLO, A. G. Nem toda pessoa cega lê em Braille nem toda pessoa surda se comunica em língua de sinais. Educação e Pesquisa, v. 33, n. 2, p. 369-386, 2007.

ULAC. Unión Latinoamericana de Ciegos. Manual técnico de servicios de rehabilitación integral para personas ciegas o con baja visión en América Latina. Uruguai: ULAC/ONCE, 2000.

ULBRICHT, V.; et al. Os Deficientes Visuais e a Educação a Distância. Revista Educa Online, v. 5, n. 3, p. $1-18,2011$.

UNESCO. Declaração de Salamanca sobre princípios, políticas e práticas na área das necessidades educativas especiais. Paris: UNESCO, 1994

VITALIANO, C. R. Análise da necessidade de preparação pedagógica de professores de cursos de licenciatura para inclusão de alunos com necessidades educacionais especiais. Revista Brasileira de Educaçáo Especial, v. 13, n. 3, p. 399-414, 2007.

\section{Notas}

${ }^{1}$ Os termos adaptaçōes curriculares e adequaçōes curriculares são utilizados como sinônimos ao longo deste artigo.

${ }^{2}$ A atividade Wiki torna possível a construçâo de um texto (com elementos multimídia) por vários participantes; cada um dos participantes fornece a sua contribuiçáo e/ou revisa o texto de maneira colaborativa.

\section{Correspondência}

Luciano Tadeu Esteves Pansanato - Universidade Tecnológica Federal do Paraná, Campus Cornélio Procópio. Avenida Alberto Carazzai, 1640, Centro, CEP: 86300-000 - Cornélio Procópio, Paraná - Brasil.

E-mail: luciano@utfpr.edu.br - luziarodrigues@utfpr.edu.br - chris.eneass@gmail.com

Recbido em 03 de março de 2015

Aprovado em 07 de março de 2016 